\title{
Glutathione Reductase, Mitochondrial
}

National Cancer Institute

\section{Source}

National Cancer Institute. Glutathione Reductase, Mitochondrial. NCI Thesaurus. Code C157042.

Glutathione reductase, mitochondrial (522 aa, $~ 56 \mathrm{kDa}$ ) is encoded by the human GSR gene. This protein plays a role in the synthesis of the sulfhydryl form of glutathione. 